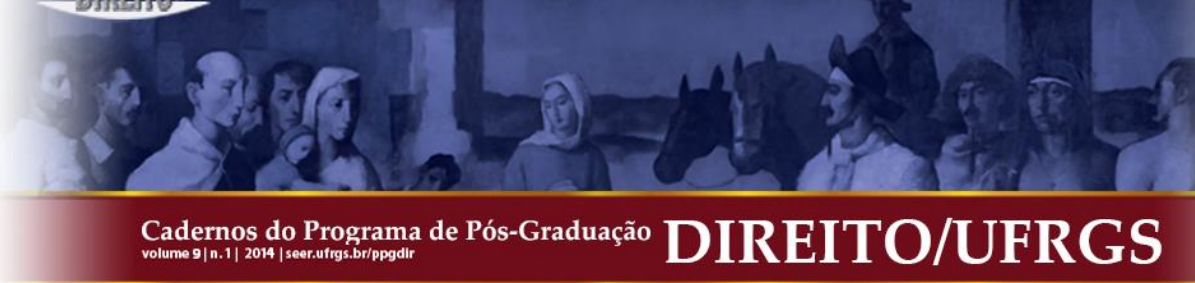

\title{
O DESENVOLVIMENTO ECONÔMICO NA AMAZÔNIA LEGAL: SEUS IMPACTOS SOCIAIS, AMBIENTAIS E CLIMÁTICOS E AS PERSPECTIVAS PARA A REGIÃo
}

\author{
ECONOMIC DEVELOPMENT IN LEGAL AMAZON: ITS SOCIAL, ENVIRONMENTAL, AND CLIMATE \\ IMPACTS AND THE PERSPECTIVES FOR THE REGION
}

Marina Courrol Ramos*

\begin{abstract}
RESUMO: O presente artigo tem por objetivo fazer uma análise dos impactos sociais, ambientais e climáticos decorrentes das várias tentativas de desenvolvimento econômico na Amazônia Legal e as perspectivas de desenvolvimento sustentável para a região a partir das políticas públicas ambientais existentes. Para tanto será feita uma análise histórica do desenvolvimento econômico da Amazônia, relacionando os ciclos econômicos com os fluxos migratórios, a questão fundiária e ambiental. Será dada ênfase à questão do desmatamento impulsionado a partir de 1970 decorrente das políticas de desenvolvimento econômico focadas em grandes obras de infraestrutura e assentamentos agrícolas, e sobre os efeitos sociais, ambientais e climáticos causados. Por fim serão analisadas as políticas públicas de combate ao desmatamento existentes e a utilização de mecanismos de incentivo como perspectiva para solucionar o problema.
\end{abstract}

PALAVRAS-CHAVE: Amazônia; Desenvolvimento Econômico; Desmatamento; Direitos Sociais; Meio Ambiente; Mudanças Climáticas.
ABSTRACT: This article aims to analyze the social, environmental, and climate impacts resulting of various attempts at economic development in the Legal Amazon and the perspectives of sustainable development for the region from the existing environmental public policies. In order to achieve this, a historical analysis of the economic development of the Amazon will be made, relating economic cycles with migration, and land and environmental issues. Emphasis will be given to the issue of deforestation driven since 1970 as a result of economic development policies focused on large infrastructure projects and agricultural settlements, and on the social, environmental, and climatic effects. Finally, public policies to combat deforestation and the use of incentive mechanisms will be analyzed as a perspective to solve the problem.

KEYWORDS: Amazon; Economic Development; Deforestation; Social Rights; Environment; Climate Changes.

SUMÁRIO: 1. As várias tentativas de desenvolvimento econômico na Amazônia legal. 2. A construção da rodovia transamazônica e o início do desmatamento. 3. Os efeitos ambientais e climáticos do desmatamento na Amazônia legal. 4. As políticas de combate ao desmatamento e as perspectivas de desenvolvimento econômico sustentável na região amazônica. Considerações finais. Referências.

\section{AS VÁRIAS TENTATIVAS DE DESENVOLVIMENTO ECONÔMICO NA AMAZÔNIA LEGAL}

Muitas foram as tentativas de povoamento e desenvolvimento de atividades econômicas na região amazônica. Durante a etapa da colonização brasileira, entre os séculos XVII e XVIII a preocupação do governo português com a região era puramente estratégica: ocupar a maior área de terras de seu território para evitar as invasões francesas, inglesas e holandesas, defendendo, por consequência, o monopólio açucareiro que predominava na região do litoral nordestino. Para tanto foram estabelecidas colônias de povoamento na região norte (diferentemente da maior parte do país, em que predominavam colônias de exploração, principalmente ligadas à economia açucareira) que, sem o apoio do governo português, se estabeleceram como uma economia extrativista baseada na mão-de-obra escrava indígena (FURTADO, 2007).

\footnotetext{
* Universidade Presbiteriana Mackenzie.
} 
Em busca da própria sobrevivência os colonos do norte se tornaram exportadores de produtos como cacau, baunilha, canela, resinas aromáticas. A colheita destes produtos dependia da mão-de-obra indígena obtida com a ajuda dos jesuítas e esta cooperação foi decisiva para a expansão territorial que se sucedeu no norte do país na primeira metade do século XVIII (FURTADO, 2007).

A região permaneceu baseada na economia extrativista florestal, principalmente no Estado do Pará, caracterizando-se por um núcleo econômico autônomo e isolado, com uma produção que apesar de contínua nunca atingiu grande expressividade econômica. Essa situação perdurou até o final do século XIX quando a borracha passou a ser o produto de maior procura do mercado internacional, principalmente devido ao fortalecimento da indústria automobilística, o "principal fator dinâmico das economias industrializadas, durante um largo período que compreende o último decênio do século XIX e os três primeiros do século XX” (FURTADO, 2007). A produção de látex passa então a ter uma demanda significativa, porém com uma oferta insuficiente por sua característica extrativista devido à falta de mão-de-obra e de grande parte das seringueiras se encontrarem em locais de difícil acesso no interior da floresta. Fazia-se necessário, portanto, aumentar a produção para atender à crescente demanda do exterior.

Uma das soluções encontradas foi atrair a mão-de-obra excedente das economias açucareiras do nordeste que se encontravam em crise. Como consequência cerca de 300 mil pessoas migram para a Amazônia Legal, entre os nos 1870 e 1912, para explorar a borracha. Outra forma de expansão do mercado foi a busca por novos pontos de extração, fazendo com que os produtores se movessem cada vez mais para o interior da floresta até então inexplorada. Conforme explica SANTOS:

\footnotetext{
As migrações transpõem a fronteira provincial do Amazonas e se dirigem aos seringais dos rios Madeira e Purus, iniciando um real devassamento e ocupação do interior do enorme vale, até então possuído pelo império do Brasil mais em termos jurídico-formal que efetivos. (SANTOS, 1980)
}

Desta forma, em 1907 para solidificar o domínio brasileiro na região e para melhor distribuição do látex do interior da floresta para os portos, inicia-se a construção da primeira estrada

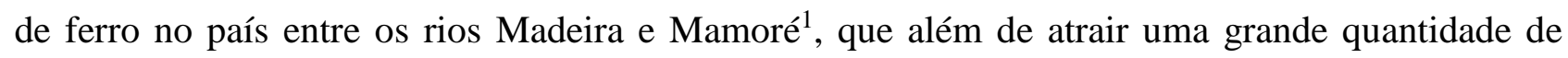

\footnotetext{
${ }^{1}$ Como forma de indenização à Bolívia, o Brasil, além de pagar a importância de 2 milhões libras esterlinas, comprometeu-se também a construir uma estrada de ferro que possibilitasse o transporte de produtos bolivianos pelo Rio Madeira.
} 
estrangeiros para sua construção ${ }^{2}$, foi responsável pela criação do município de Porto Velho, Estado de Rondônia. A estrada de ferro Madeira-Mamoré funcionou plenamente de 1911 até 1957 atendendo tanto ao escoamento da produção de borracha, como ao fluxo de passageiros. Após um período de falta de investimentos por parte do governo, que havia assumido a concessão da ferrovia, foi determinada sua desativação em 1966 para a construção de uma rodovia.

No apogeu do ciclo da borracha a região da Amazônia Legal foi responsável pela produção de $2 / 3$ de toda a borracha consumida no mundo. Como a seringueira é uma planta originária da região amazônica, o Brasil permaneceu como seu principal exportador até o segundo decênio do século XX quando perdeu o monopólio para a borracha asiática (FURTADO, 2007). No ano de 1875 o inglês Henry Alexander Wickham exportou ilegalmente cerca de 70 mil sementes de seringueira para o jardim botânico de Londres (Kew Garden) para a posterior plantação na Ásia, sendo este considerado um dos casos mais emblemáticos de biopirataria no país. Como os asiáticos produziam a borracha de forma sistemática (ao contrário do Brasil que tinha uma produção extrativista), por volta de 1914 estes passam a ser os maiores produtores de borracha do mundo. Com a queda mundial dos preços devido ao aumento da oferta asiática a produção brasileira de borracha entra em crise (DRUMMOND, 2009).

Em 1927, na tentativa de se tornar independente da produção asiática de borracha, o empresário Henry Ford consegui a concessão de uma enorme quantidade de terras às margens do rio Tapajós, no Estado do Pará, para a plantação de seringueiras (GRANDIN, 2009). O projeto de Ford de produção sistemática de seringueiras contou com o total apoio do governo Getúlio Vargas, que via no projeto uma nova oportunidade de se restabelecer a economia da borracha. Para tanto, além da concessão terras, prontificou-se a recrutar trabalhadores para a região.

A produção se iniciou com perspectivas muito promissoras, entretanto, em 1942 a plantação foi atacada por uma praga que acabou com toda a perspectiva de produção de borracha. Em 1945 Henry Ford se retira do Brasil abandonando a Companhia Ford Industrial do Brasil. Com o restabelecimento o mercado asiático após a guerra e a introdução da produção sintética de borracha no mercado internacional, o mercado brasileiro entra definitivamente em decadência, se mantendo até hoje com uma pequena produção extrativista de borracha, principalmente para o mercado interno.

Durante os anos 1950 e 1970 não houve grandes tentativas de desenvolvimento na região amazônica, salvo alguns empreendimentos isolados. O que se observa, no entanto, é que apesar dos

\footnotetext{
${ }^{2}$ A construção desta ferrovia levou para a região cerca de 20.000 trabalhadores vindos de várias partes do mundo, entretanto, cerca de 7.000 destes trabalhadores sucumbiram em decorrência da malária.
} 


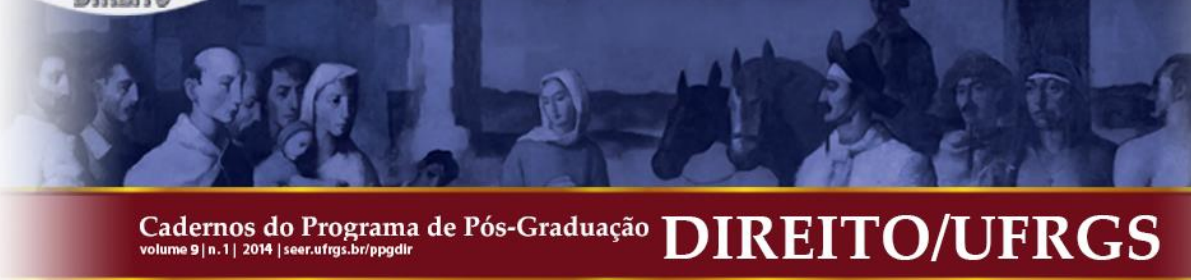

diversos fluxos migratórios e das tentativas de desenvolvimento econômico da região, do ponto de vista ambiental, até os anos 1970 a floresta amazônica manteve aproximadamente 90\% de sua cobertura intacta, sendo que o efetivo desmatamento e degradação se iniciou com a abertura de estradas (oficiais e não oficiais), em especial com a construção da rodovia Transamazônica, que passou a cortar a Amazônia Legal de leste a oeste (FEARNSIDE, 2005).

\section{A CONSTRUÇÃo DA RODOVIA TRANSAMAZÔNICA E O INÍCIO DO DESMATAMENTO}

Em 1972 foi lançado pelo governo de Emilio Médici o Plano de Integração Nacional (PIN), como forma de integrar economicamente a região norte ao restante do país. Para implementação do plano iniciou-se a construção da rodovia Transamazônica (BR-230) que liga o município de Cabedelo, no litoral da Paraíba ao município de Lábrea, no Amazonas, com 4.223 km de extensão. ${ }^{3}$ Simultaneamente o governo federal promoveu uma campanha de migração para a ocupação econômica da região, proporcionando a transferência de cerca de 6.000 famílias para os assentamentos agrários, as chamadas agrovilas, que foram se formando às margens da rodovia, principalmente no Estado do Pará.

Além de se tratar de uma obra de custo elevado e sem função efetiva - já que o transporte fluvial seria o mais adequado do ponto de vista econômico e ambiental em uma região rica em recursos hídricos -, a sua construção deu início, ainda, ao desmatamento sistemático da floresta, não só como consequência do povoamento da região, como também pela exploração de madeira, o avanço da agropecuária de larga escala e da agricultura de subsistência itinerante, formando-se o chamado "arco do desmatamento". FERREIRA, VENTICINQUE e ALMEIDA com de forma sucinta apontam as características do processo de desmatamento que teve início nos anos 1970 e persiste até hoje:

\footnotetext{
O processo de desmatamento normalmente começa com a abertura oficial ou clandestina de estradas que permitem a expansão humana e a ocupação irregular de terras à exploração predatória de madeiras nobres. Posteriormente, converte-se a floresta explorada em agricultura familiar e pastagens para a criação extensiva de gado, especialmente em grandes propriedades, sendo este fator responsável por cerca de $80 \%$ das florestas desmatadas na Amazônia Legal. Mais recentemente, as pastagens estão dando lugar à agricultura mecanizada, principalmente àquela ligada às culturas de soja e algodão. (FERREIRA, VENTICINQUE e ALMEIDA, 2005)
}

\footnotetext{
${ }^{3}$ Pelo projeto original a rodovia iria até o município de Benjamin Constant, na fronteira do Brasil com o Peru e Equador, com $4.977 \mathrm{~km}$, mas a construção foi abandonada.
} 


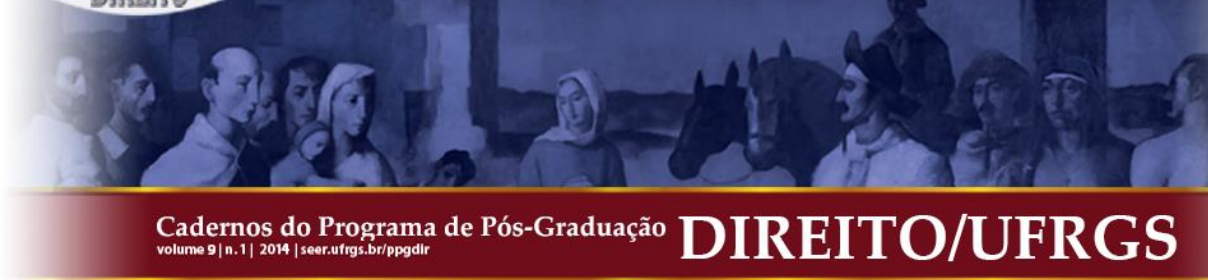

De acordo com levantamentos feitos pela Superintendência do Desenvolvimento da Amazônia Legal, no período de 1970 a 2000 a população da Amazônia Legal passou de 7,3 milhões de habitantes para 21 milhões, e em 2010 já atingia 25,4 milhões de habitantes (SUPERINTENDÊNCIA DO DESENVOLVIMENTO DA AMAZÔNIA LEGAL, 2013). Segundo estudos do IPEA até 1960 a população na Amazônia Legal estava dispersa ao longo dos rios com uma baixa densidade demográfica. A partir de 1970 há um aumento populacional de cerca de $350 \%$ ao longo das rodovias que se construíram, com uma progressiva taxa de urbanização (AZEREDO, 2013).

Temos que ressaltar, entretanto, que a construção de estradas não é o único fator responsável pelo desmatamento, mas sim um dos fatores que compõe a problemática. Com a abertura das estradas iniciou-se também a especulação de terras e a formação de cidades impondo um novo perfil à exploração econômica da região. Durante os anos 1970 até início dos anos 1990 fazendeiros e industriais se beneficiaram com incentivos fiscais e créditos a juros baixos, promovidos pelo governo como forma de incentivar o investimento econômico na Amazônia Legal.

Como consequência das políticas de incentivo formaram-se os grandes e médios latifúndios para a criação de gado, agricultura mecanizada e exploração de madeiras nobres que resultaram no aumento gradativo do desmatamento e degradação da floresta (MARGULIS, 2003). A renda se concentrou nas mãos de uma minoria e a maioria da população vive em um sistema de subsistência bastante precário.

Conforme ressalta Bertha Becker uma solução tanto para a questão social, como ambiental, seria a implementação de uma política regional de desenvolvimento, consolidando os povoamentos existentes, elevando-se a produtividade dos pequenos produtores e promovendo a proteção ambiental, por meio da utilização de instrumentos econômicos de incentivo (BECKER, 2005).

\section{OS EFEITOS AMBIENTAIS E CLIMÁTICOS DO DESMATAMENTO NA AMAZÔNIA LEGAL}

A Amazônia Legal representa um papel de suma importância no mundo por ser a região de maior biodiversidade do mundo, apenas como exemplo, estima-se que $10 \%$ das espécies de plantas do mundo estejam localizadas na floresta amazônica. Além disso, a floresta representa um papel importante na regulação do clima influindo diretamente nas estações de chuva, nos níveis dos rios e reservatórios de água. Por essa razão o Brasil sofre grande pressão internacional para conter as altas 
taxas de desmatamento, que colocam em risco importantes serviços ambientais, diversas espécies de fauna e flora, além de contribuir com aquecimento global.

A floresta possui um grande número de espécies, que por sua vez possuem papel fundamental na preservação do patrimônio genético do país e manutenção dos conhecimentos tradicionais de populações indígenas. Outro papel fundamental da floresta está no ciclo das águas. A Amazônia Legal detém grande parte da reserva mundial de água doce, respondendo por cerca de 1/5 do volume de água lançado atualmente nos oceanos (MARCOVITCH, 2012). Esta imensa quantidade de água tem grande importância para a regulação do clima no Brasil e nos países vizinhos.

A necessidade de proteção ambiental da Amazônia Legal é inquestionável, havendo uma percepção de que a perda ambiental gerada pelo desmatamento é inúmeras vezes maior do que o ganho econômico das atividades degradadoras.

Os impactos negativos do desmatamento são significativos e interligados, pois além da degradação ambiental o corte ou queima das florestas libera gases de efeito estufa (GEE) ${ }^{4}$, responsáveis pelo aquecimento global, que por sua vez influi diretamente nos ciclos das águas, que afetam diretamente a biodiversidade.

Segundo dados do $5^{\circ}$ relatório do $\operatorname{IPCC}^{5}$ a projeção de diminuição da humidade natural e aumento de temperatura para a Amazônia Legal até o final do século é significativa, havendo possibilidade de savanização de algumas regiões. Esses fenômenos estão diretamente associados ao aumento da temperatura causados pelas mudanças climáticas. Diante destas perspectivas há necessidade de adoção de medidas contra o desmatamento da Amazônia Legal que contribui com $77 \%{ }^{6}$ das emissões de GEE, tornando o Brasil um dos cinco maiores emissores do mundo.

\footnotetext{
${ }^{4}$ A Convenção Quadro das Nações Unidas sobre Mudança do Clima e o Protocolo de Quioto (Anexo A) definem os gases de efeito estufa (GEE) como sendo: dióxido de carbono $\left(\mathrm{CO}_{2}\right)$, metano $\left(\mathrm{CH}_{4}\right)$ óxido nitroso $\left(\mathrm{N}_{2} \mathrm{O}\right)$, além de mais três gases sintéticos hidrofluorcarbonos ( $\mathrm{HFCs}$ ), perfluorcarbonos ( $\mathrm{PFCs})$ e hexafluoreto de enxofre $\left(\mathrm{SF}_{6}\right)$.

${ }^{5}$ O $5^{\circ}$ relatório do Intergovernmental Panel for Climate Change - IPCC (AR5) foi publicado em 27.09.2013. Disponível em: <http://www.climatechange2013.org/images/uploads/WGIAR5-SPM_Approved27Sep2013.pdf〉. Acesso em: 31 out. 2013.

${ }^{6}$ Dados do Segundo Inventário Brasileiro de Emissões e Remoções Antrópicas de Gases de Efeito Estufa, referente ao período de 1990 a 2005.
} 


\section{AS POLÍticas DE COMBATE AO DESMATAMENTO E AS PERSPECTIVAS DE DESENVOLVIMENTO ECONÔMICO SUSTENTÁVEL NA REGIÃO AMAZÔNICA}

Mesmo não tendo assumido metas quantitativas de redução de GEE - por não ter obrigação legal -, o Brasil tem atuado no sentido de cumprir com os compromissos assumidos durante a $15^{\mathrm{a}}$ Conferência das Partes em Copenhagen (COP15), ou seja, adotar Ações de Mitigação Nacionalmente Apropriadas (Nationally Appropriate Mitigation Actions - NAMAs) ${ }^{7}$. Para tanto, em dezembro de 2009 o governo federal promulgou a Lei Federal $n^{\circ}$ 12.187/2009 (Política Nacional sobre Mudança do Clima - PNMC) em que o país assume o compromisso voluntário nacional de reduzir suas emissões antrópicas de gases de efeito estufa entre 36,1\% e 38,9\% projetadas até 2020, e deu maior ênfase à implementação dos planos setoriais de combate ao desmatamento como o Plano de Prevenção e Controle do Desmatamento na Amazônia Legal PPCDAm e o Plano de Ação e Controle do Desmatamento e das Queimadas no Cerrado PPCerrado.

Como resultado principalmente das ações de monitoramento e fiscalização houve uma queda no desmatamento da Amazônia Legal de 84\%, levando-se em consideração o índice de desmatamento entre os anos de $2004\left(27.772 \mathrm{~km}^{2}\right)$ e $2012\left(4.571 \mathrm{~km}^{2}\right)$, segundo dados do Instituto de Pesquisas Espaciais (INPE) ${ }^{8}$.

Entretanto, esta conquista pode estar em risco uma vez que após a aprovação da Lei 12.651/2012 que instituiu o novo Código Florestal, consolidando áreas desmatadas até 2008 e diminuindo áreas de preservação e conservação de recursos naturais, foi verificando um aumento de $28 \%{ }^{9}$ na taxa de desmatamento na Amazônia Legal que vinha caindo ano a ano. Acredita-se que este aumento seja resultado da sensação de impunidade provocada pela nova lei e do aumento da especulação fundiária decorrente das obras de infraestrutura na região, como a construção do porto de Santarém, asfaltamento da Rodovia Transamazônica e construção de hidrelétricas.

Há uma clara falta de coordenação entre políticas públicas na área ambiental, incentivando, ainda que de forma indireta, o desmatamento pontual, muitas vezes imperceptível por meio do

\footnotetext{
${ }^{7}$ Ações de Mitigação Nacionalmente Apropriadas são esforços voluntários assumidos e adotados pelos países nãoAnexo I do Protocolo de Quioto, apresentados na COP15 (Copenhagen) e depositadas oficialmente na CQNUMC, visando a mitigação de emissão de GEE.

${ }^{8}$ Dados obtidos no Instituto Nacional de Pesquisas Especiais (INPE) que monitora o desmatamento na Amazônia Legal por meio do Programa de Cálculo do Desflorestamento da Amazônia Legal (PRODES). Disponível em: <http://www.obt.inpe.br/prodes/index.php>. Acesso em: 19 set. 13.

9 Estimativa PRODES 2013. Disponível em: <http://www.obt.inpe.br/prodes/Prodes_Taxa2013.pdf〉. Acesso em: 17 nov. 2013.
} 
monitoramento via satélite, especialmente no chamado arco do desmatamento em razão de práticas agrícolas e pecuária.

O grande desafio da região amazônica, portanto, será manter os índices de queda no desmatamento ilegal e ao mesmo tempo promover a integração social e econômica das populações que dependem da floresta como meio de subsistência, por meio da regularização fundiária e práticas sustentáveis de agricultura, pecuária e de manejo florestal.

Muito se discute atualmente sobre a ineficácia da utilização exclusiva de instrumentos de comando e controle para a proteção ambiental. O que se tem visto na prática é que este tipo de mecanismo, que apesar de indispensável, não tem surtido o efeito necessário para a efetiva proteção dos recursos naturais a longo prazo, pois surtem o efeito de reprimir ações, mas não de mudar comportamentos.

O Brasil é considerado um país pioneiro em termos de normas de proteção ambiental, entretanto, o nível de cumprimento destas normas ainda é relativamente baixo. Por essa razão, a utilização de instrumentos econômicos é apontada como um mecanismo suplementar necessário à proteção ambiental, por ter a característica de incentivar comportamentos positivos de proteção ao meio ambiente. Além disso, por meio desses instrumentos a proteção ambiental não estaria concentrada nas mãos de um único ator (Poder Público), mas sim de vários atores. Portanto, ao combinar uma série de mecanismos de proteção estar-se-ia aprimorando a governança ambiental.

Dentre os instrumentos econômicos de proteção ambiental poderia se destacar: a) os fiscais, onde ações de proteção ambiental poderiam ser beneficiadas com isenções de tributos ou redução de alíquotas e b) econômicos e financeiros como financiamento de ações de proteção por meio de fundos específicos, a Reduções de Emissões por Desmatamento e Degradação com atividades de conservação, manejo sustentável das florestas e aumento de seus estoques de carbono em países em desenvolvimento (REDD+) e os Pagamentos por Serviços Ambientais (PSA).

Hoje discute-se muito o papel do mecanismo do REDD $+{ }^{10}$, como um instrumento de incentivo para ações de mitigação das emissões brasileiras de gases de efeito estufa, por meio de compensação financeira para aqueles que promovam a "manutenção da floresta em pé". Entretanto, sua aplicação ainda é bastante questionável por falta de uma regulamentação interna (e

\footnotetext{
${ }^{10}$ Inicialmente a sigla REDD se referia apenas ao mecanismo de Redução de Emissões por Desmatamento e Degradação, ainda em negociação na ONU, possibilitaria a remuneração daqueles que conservam a floresta em pé. Com o tempo este conceito foi sendo ampliado e hoje adota-se o chamado REDD+ (REDD plus) que abrange também as atividades de conservação, manejo sustentável das florestas e aumento dos estoques de carbono nos países desenvolvidos. Apesar de ser um mecanismo ainda em negociação no âmbito da ONU ele já vem sendo aplicado a projetos negociados no chamado mercado voluntário de carbono.
} 
internacional) adequada ${ }^{11}$, havendo grande dúvida se este seria um real instrumento positivo de mitigação de emissões de gases de efeito estufa ou não.

A primeira grande dúvida, que inclusive divide os países defensores deste mecanismo, é sobre a possibilidade dele servir internacionalmente para o cômputo de redução de emissões dos países com metas quantificadas ou se serviria apenas como um sistema de financiamento de ações voluntárias de mitigação nos países em desenvolvimento (NAMAs) por meio de fundos específicos $^{12}$. Ou seja, se o mecanismo funcionaria como um instrumento de mercado ou como um instrumento de financiamento para países em desenvolvimento. O posicionamento do Brasil nas Conferências das Partes (COP) até então sempre foi o de que o instrumento não pudesse ser utilizado pelos países desenvolvidos para abatimento de suas metas obrigatórias de redução de emissão, mas sim como uma medida adicional de redução das emissões globais na forma de financiamento de ações nos países em desenvolvimento.

Outra questão que surge diz respeito ao mercado de ativos ambientais decorrente dos projetos de REDD+ desenvolvidos no país. Estes projetos não se enquadram no chamado mercado regulado, regido pelas normas estabelecidas pelo Protocolo de Quioto, mas são desenvolvidos nos países em desenvolvimento e regulados pelo chamado mercado voluntário de carbono com uma gama de diferentes tipos de "standards". Justamente por não se tratar de uma atividade regulamentada questiona-se tanto a efetiva redução de emissões de GEE - uma vez que o monitoramento da manutenção da "floresta em pé" e a permanência dos estoques de carbono é bastante complicado -, como a questão social relacionada a estes projetos.

Normalmente estes projetos são firmados por meio de contratos particulares que nem sempre garantem um equilíbrio econômico e financeiro adequado entre os participantes, sendo muito mais lucrativos aos investidores - em sua grande parte estrangeiros - do que para a população local, sendo muitas delas comunidades tradicionais e povos indígenas.

A preocupação em proteger o interesse dos povos indígenas resultou no Parecer 02/2012 da Advocacia Geral da União (AGU), como resposta a consulta da Procuradoria Federal Especializada

\footnotetext{
${ }^{11}$ Há o Projeto de Lei (PL 195/2011) que prevê a instituição do sistema nacional de redução de emissões por desmatamento e degradação, conservação, manejo florestal sustentável, manutenção e aumento dos estoques de carbono florestal que ainda encontra-se em discussão na Câmara dos Deputados.

${ }^{12}$ Durante a COP19 em Varsóvia houve avanços sobre o mecanismo do REDD+ no âmbito da ONU, tendo sido firmado o Quadro Varsóvia para o REDD+ (Warsaw Framework for REDD+), documento que dispõe sobre algumas regras que devem ser observadas no caso de financiamento e investimento em projetos de REDD+ nos países em desenvolvimento, tais como a publicidade dos dados dos projetos incluindo o valor dos recursos financiados e os resultados do projeto expressos em toneladas de carbono equivalentes. Desta forma podemos notar que as negociações da ONU estão mais tendentes ao REDD+ como uma forma de financiamento de NAMAS, inclusive se utilizando do Fundo Verde do Clima do que como um mecanismo de mercado.
} 
da Fundação Nacional do Índio (FUNAI), questionando os recentes contratos de comercialização de créditos de carbono firmados entre tribos indígenas e investidores estrangeiros. De acordo com o mecanismo dos projetos de REDD+ as comunidades promoveriam a conservação e preservação da “floresta em pé” em troca de uma compensação financeira. O problema é que por se tratar de contratos especulativos - por ainda não haver regulamentação internacional ou nacional sobre este mecanismo - , a expectativa de remuneração financeira destes povos poderia ser frustrada no futuro. Ademais, as atuais e futuras gerações destes povos indígenas ficariam privados do usufruto de suas terras por longos períodos - já que estes contratos normalmente abrangem períodos de 20 a 40 anos - restringindo-os de suas atividades produtivas de subsistência e manejo dos recursos naturais, ou seja, estaria sendo violado o princípio da solidariedade intergeracional. Além disso, estes contratos podem servir também de instrumentos para o e acesso não consentido ao patrimônio genético do país com a exploração ilegal do conhecimento tradicional destas comunidades.

Apesar de ser um mecanismo que suscita muitas dúvidas quanto à sua eficácia, há, por outro lado, aqueles que o defendem como uma forma incentivar a população local a trocar o desmatamento por uma forma mais rentável de ocupação, que poderia se dar tanto por meio do mecanismo de mercado como por meio do mecanismo do PSA, pois o REDD+ também propicia este tipo de retribuição.

$\mathrm{O}$ instrumento de PSA propriamente dito está fundamentado no princípio do protetor recebedor que busca premiar o comportamento voluntário de proteção de um serviço ecossistêmico. Derivado do princípio do usuário pagador, previsto no artigo $4^{\circ}$, VII, que prevê a obrigação do usuário de recursos naturais (em sua atividade econômica) de contribuir por esse uso. Por meio de criação doutrinária, portanto, o princípio do protetor recebedor procurou premiar aquele que ao invés de se utilizar do recurso natural, voluntariamente deixa de fazê-lo como forma de proteção. Cabe ressaltar, no entanto, que o instrumento não premia aquele que tem um dever legal de reparar o meio ambiente que foi por ele degradado em caso de dano, mas sim incentivar aquele que não tem o dever legal a manter, recuperar e restabelecer um ecossistema relevante. Conforme salienta Alexandre Altmann "a tônica dos planos e programas de PSA deve ser a preservação das áreas prioritárias para a conservação da biodiversidade e beleza cênica" (RECH; ALTAMANN, 2009).

Apesar de não haver regulamentação do PSA em âmbito nacional ${ }^{13}$, a Lei 12.651/2012, que instituiu o Novo Código Florestal, prevê em seu artigo 41, a possibilidade de "pagamento ou

\footnotetext{
${ }^{13}$ Tramita na Câmara dos Deputados o Projeto de Lei 792/2007, ao qual estão apensados outros dez projetos de lei relacionados, que prevê a regulamentação do instrumento de PSA na forma de incentivo financeiro para a recuperação, manutenção e melhoria de alguns serviços ecossistêmicos promovidas por comunidades tradicionais e pequenos
} 
incentivo a serviços ambientais como retribuição monetária ou não às atividades de conservação $e$ melhoria dos ecossistemas" que gerem a redução das emissões ou manutenção e aumento dos estoques de carbono, além de outros instrumentos de incentivos como linhas de financiamento, concessão de créditos reembolsáveis e não reembolsáveis de fundos públicos (como é o caso do Fundo Clima) e benefícios fiscais. O artigo ainda estimula a criação de um mercado de serviços ambientais, prevendo que este deva ser integrado a um sistema em âmbito nacional ou estadual, que ainda deverá ser criado e regulamentado. No caso da Amazônia Legal, o mecanismo tem sido aplicado sob a forma de remuneração às populações tradicionais que prestam o serviço ambiental de manutenção da florestas em pé. O Estado do Acre, por exemplo, promulgou a Lei Estadual 2.308/2010 que instituiu um Sistema Estadual de Incentivos a Serviços Ambientais - SISA, onde são previstos programas, planos e projetos que beneficiam os provedores de serviços ambientais. Já no Estado do Amazonas foi instituído o programa Bolsa Floresta implementado por meio do Decreto Estadual no 26.958/2007, que prevê o pagamento de um valor mensal às famílias de baixa renda que protejam a floresta da degradação, tem o objetivo de ser uma renda extra para estas famílias.

O que se questiona, entretanto, é qual o efetivo custo social do PSA e qual valor seria suficiente para que ele efetivamente funcione como um instrumento modificador de comportamentos, de governança ambiental dos recursos naturais? Esta é uma das perguntas que permanece sem respostas.

\section{CONSIDERAÇÕES FINAIS}

Pode-se dizer que o desmatamento e degradação da Amazônia Legal sempre estiveram ligados aos fluxos migratórios e tentativas de desenvolvimento econômico da região. Percebe-se, entretanto, que apesar dos diversos fluxos migratórios a cobertura vegetal permanecia praticamente integra até o início dos anos 1970, havendo determinados focos ligados aos povoamentos que se estabeleciam.

Com a aberturas de estradas, que possibilitou a ocupação mais fácil de terras mais distantes e os incentivos fiscais e creditícios observou-se a modificação no perfil econômico da região, que

produtores rurais, visando a preservação de áreas prioritárias para a conservação da biodiversidade e beleza cênica, recuperação de áreas degradadas, formação de corredores ecológicos e desestímulo ao desmatamento para fins agrícola e pecuário. 
passou a contar com grandes latifúndios voltados para a pecuária, a plantação de monoculturas e a exploração da madeira. Como consequência desta política econômica as taxas de desmatamento passaram a crescer acentuadamente ano após ano, mantendo-se nesta crescente mesmo em tempos de crise financeira.

Ocorre que o desmatamento traz consequências negativas muito maiores do que os benefícios econômicos, pois estes se concentram nas mãos de uma minoria, enquanto a grande maioria vive em situação de subsistência e muitas vezes privada do acesso aos recursos naturais. Além disso, o desmatamento provoca severos impactos ambientais negativos como a perda da biodiversidade, modificação nos ciclos das chuvas e contribui para o aquecimento global.

Desta forma, se faz necessário modificar o perfil das atividades econômicas que se desenvolvem na Amazônia Legal, não só em razão da questão ambiental que afeta a todos, como também devido ao aspecto social que afeta a população tradicional da região. Conforme pondera Jacques Marcovitch:

o leque de prioridades na Amazônia Legal que tem o REDD como iniciativa de emergência, abrange: regularização fundiária, combate ao desmatamento, amparo ao extrativismo e pequenos produtores agrícolas, transporte multimodal integrado, capacitação profissional de trabalhadores e um novo perfil industrial. (MARCOVITCH, 2012)

Não estamos diante de uma solução única, mas sim da necessidade de implementação de um conjunto de ações e políticas públicas socioambientais que deverão ser integradas.

Apesar de todos os esforços do governo brasileiro em contenção do desmatamento, até certo ponto muito bem sucedido, o que se verifica é que a efetiva proteção dos recursos ambientais da Amazônia Legal ainda é deficiente, uma vez que a pressão sobre estes recursos ainda persiste, acentuada sobretudo por políticas contraditórias, como o Código Florestal recentemente aprovado.

Enquanto houver o abismo social que caracteriza a região, onde uma minoria se beneficia com a exploração indiscriminada dos recursos florestais, enquanto a maioria vive em condições de miséria, a proteção ambiental não será efetiva e, portanto, não se poderá falar em governança ambiental eficiente.

Para tanto se fala sobre a aplicação de instrumentos de incentivo como o REDD+ e o PSA como forma de incentivar a mudança de comportamento daqueles que exploram o desmatamento, oferecendo uma recompensa financeira para a manutenção e recuperação dos recursos naturais e combate ao desmatamento, mas ainda há muita dúvida sobre a efetiva proteção ambiental e quais benefícios sociais tais instrumentos possam gerar. 


\section{REFERÊNCIAS}

AZEREDO, Luiz Cesar Loureiro de. Apontamentos sobre a população do Brasil. Repositório do Conhecimento do Instituto de Pesquisa Econômica Aplicada, 2013. Disponível em: <http://repositorio.ipea.gov.br/bitstream/11058/1038/1/Apresentação_Apontamentos_sobre_a_popu lação_do_Brasil.pdf>. Acesso em 05 fev. 2014.

BECKER, Bertha. Amazônia Legal: Projeto nacional, política regional e instrumentos econômicos. In Instrumentos econômicos para o desenvolvimento sustentável na Amazônia Legal brasileira. Peter H. May, Carlos Amaral, Brent Milikan, Petra Ascher [et al] organizadores. Brasília: Ministério do Meio Ambiente, 2005.

BRASIL. Lei 12.187/2009. Política Nacional sobre Mudanças do Clima. Disponível em: <http://www.planalto.gov.br/ccivil_03/_ato2007-2010/2009/lei/112187.htm>. Acesso em 17 out. 2012.

MCTI. Acordo de Copenhagen de 2009. Disponível em: < http://www.mct.gov.br/upd_blob/0211/211585.pdf >. Acesso em 15 out. 2012.

MCTI. Estimativas anuais de emissões de gases de efeito estufa no Brasil. 2013. Disponível em: <http://gvces.com.br/arquivos/177/EstimativasClima.pdf>. Acesso em: 12 nov. 2013.

. MCTI. Segundo Inventário Brasileiro de Emissões e Remoções Antrópicas de Gases de Efeito Estufa, referente ao período de 1990 a 2005. Disponível em: <http://www.mct.gov.br/upd_blob/0214/214061.pdf>. Acesso em: 17.03.2013.

CRAIG, Neville B. A Estrada de Ferro Madeira-Mamoré: história trágica de uma expedição. São Paulo: Companhia Editora Nacional, 1947. Disponível em: $<$ http://www.brasiliana.com.br/obras/estrada-de-ferro-madeira-mamore-historia-tragica-de-umaexpedicao/pagina/1/texto>. Acesso em 03 fev. 2014. Disponível em Brasiliana Eletrônica

DOMINGUES, Mariana Soares; BERMANN, Célio. O arco de desflorestamento na Amazônia Legal: da pecuária à soja. Ambient. soc. [online], vol.15, n.2, pp. 1-22, 2012.

DRUMMOND, José Augusto. Aventuras e desventuras de um biopirata. Boletim do Museu Paraense Emilio Goeldi. Ciências Humanas, v. 4, n. 3, p. 549-552, 2009. Disponível em: 
<http://www.scielo.br/scielo.php?pid=S1981-81222009000300012\&script=sci_arttext\&tlng=es . Acesso em 03 fev. 2014.

FEARNSIDE, Philip M. Desmatamento na Amazônia Legal brasileira: história, índices e consequências. Megadiversidade, v. 1, n. 1, p. 113-123, 2005.

FEARNSIDE, Philip M. Desmatamento na Amazônia Legal: dinâmica, impactos e controle. Acta Amazônica, v. 36, n. 3, p. 395-400, 2006.

FERREIRA, Heline S.; FERREIRA, Maria Leonor P. C.; DE ARAÚJO AYALA, Patryck. Mudanças Climáticas e Biodiversidade: a vulnerabilidade da floresta amazônica em face da crescente demanda por etanol. REID - Revista Eletrônica Internacional Direito e Cidadania, Disponível em: <http://www.reid.org.br/print.php?CONT=00000246>. Acesso em: 31 out. 2013.

FERREIRA, Leandro Valle; VENTICINQUE, Eduardo; ALMEIDA, Samuel. O desmatamento na Amazônia Legal e a importância das áreas protegidas. Estud. av. [online], vol.19, n.53, pp. 157-166, 2005.

FURTADO, Celso. Formação Econômica do Brasil. São Paulo: Companhia das Letras, 2007.

GASQUES, João Garcia. Padrão de crescimento da Amazônia Legal e instrumentos econômicos. In Instrumentos econômicos para o desenvolvimento sustentável na Amazônia Legal brasileira. Peter H. May, Carlos Amaral, Brent Milikan, Petra Ascher [et al] organizadores. Brasília: Ministério do Meio Ambiente, 2005.

GRANDIN, Greg. Fordlandia: the rise and fall of Henry Ford's forgotten jungle city. Macmillan, 2009.

LIMA, Deborah; POZZOBON, Jorge. Amazônia Legal socioambiental: sustentabilidade ecológica $e$ diversidade social. Estud. av. [online]. 2005, vol.19, n.54, pp. 45-76. ISSN 0103-4014. Disponível em: <http://www.scielo.br/pdf/ea/v19n54/03.pdf>. Acesso em: 16 out. 2013.

MARCOVITCH, Jacques. A governança internacional do meio ambiente. In Ribeiro, Wagner Costa, Org. Governança da ordem ambiental internacional e inclusão social. São Paulo, Annablume; Procam; IEE, 2012.

MARCOVITCH, Jacques; MARGULIS, Sergio; DUBEUX, Carolina B. S. Economia da mudança do clima no Brasil: custos e oportunidades. São Paulo: IBEP Gráfica, 2010. 
MARGULIS, Sergio. Causas do desmatamento da Amazônia Legal brasileira. Brasília: Banco Mundial, 2003.

MOTTA, Ronaldo Serôa. Instrumentos econômicos e política ambiental. In Instrumentos econômicos para o desenvolvimento sustentável na Amazônia Legal brasileira. Peter H. May, Carlos Amaral, Brent Milikan, Petra Ascher [et al] organizadores. Brasília: Ministério do Meio Ambiente, 2005.

REIS, Eustaquio J. et al. Perspectivas econômicas do desflorestamento da Amazônia Legal. IPEA, 1991. Disponível em: <http://www.sae.gov.br/site/wp-content/uploads/td_0215.pdf>.

RIBEIRO, Wagner Costa; SANT'ANNA, Fernanda Melo. Governança da Ordem Ambiental Internacional. In: RIBEIRO, Wagner Costa (Org.). Governança da ordem ambiental internacional e inclusão social. São Paulo, Annablume; Procam; IEE, 2012.

SANTOS, Roberto. História econômica da Amazônia Legal (1800-1920). São Paulo: TA Queiroz, 1980.

SECRETO, María Verónica. Mais Borracha Para A Vitória. Campanha de recrutamento de trabalhadores e fracasso social na exploração de borracha durante o governo Vargas. Estudios Rurales. Publicación de Centro de Estudios de La Argentina Rural. Bernal, Vol. 1 No 1, p. 79-107, 2011.

SUPERINTENDÊNCIA DO DESENVOLVIMENTO DA AMAZÔNIA LEGAL (Sudam). Demografia. Disponível em: <http://www.sudam.gov.br/amazonia-legal/demografia>. Acesso em: 31 out. 2013.

SUPERINTENDÊNCIA DO DESENVOLVIMENTO DA AMAZÔNIA LEGAL (Sudam) e ORGANIZAÇÃO DOS ESTADOS AMERICANOS (OEA). Boletim com indicadores socioeconômicos-ambientais e análise conjuntural da Amazônia Legal Legal. Belém: SUDAM, 2012.

Submissão: $12 / 02 / 2014$ Aceito para Publicação: 03/06/2014 